\title{
Arterial Spin-Labeling in Children with Brain Tumor: A Meta-Analysis
}

\author{
(D)A.F. Delgado, (D)F. De Luca, (D) P. Hanagandi, (DD. van Westen, and (D)A.F. Delgado
}

\section{ABSTRACT}

BACKGROUND: The value of arterial spin-labeling in a pediatric population has not been assessed in a meta-analysis.

PURPOSE: Our aim was to assess the diagnostic accuracy of arterial spin-labeling-derived cerebral blood flow to discriminate low- and high-grade tumors.

DATA SOURCES: MEDLINE, EMBASE, the Web of Science Core Collection, and the Cochrane Library were used.

STUDY SELECTION: Pediatric patients with arterial spin-labeling MR imaging with verified neuropathologic diagnoses were included.

DATA ANALYSIS: Relative CBF and absolute CBF and tumor grade were extracted, including sequence-specific information. Mean differences in CBF between low- and high-grade tumors were calculated. Study quality was assessed.

DATA SYNTHESIS: Data were aggregated using the bivariate summary receiver operating characteristic curve model. Heterogeneity was explored with meta-regression and subgroup analyses. The study protocol was published at PROSPERO (CRD42017075055). Eight studies encompassing 286 pediatric patients were included. The mean differences in absolute CBF were $29.62 \mathrm{~mL} / \mathrm{min} / 100 \mathrm{~g}(95 \% \mathrm{Cl}, 10.43-48.82$ $\mathrm{mL} / \mathrm{min} / 100 \mathrm{~g}), \mathrm{I}^{2}=74, P=.002$, and $1.34 \mathrm{~mL} / \mathrm{min} / 100 \mathrm{~g}(95 \% \mathrm{Cl}, 0.95-1.74 \mathrm{~mL} / \mathrm{min} / 100 \mathrm{~g}), P<.001, \mathrm{I}^{2}=38$ for relative CBF. Pooled sensitivity for relative $C B F$ ranged from 0.75 to 0.90 , and specificity, from 0.77 to 0.92 with an area under curve $=0.92$. Meta-regression showed no moderating effect of sequence parameters TE, TR, acquisition time, or ROI method.

LIMITATIONS: Included tumor types, analysis method, and original data varied among included studies.

CONCLUSIONS: Arterial spin-labeling-derived CBF measures showed high diagnostic accuracy for discriminating low- and high-grade tumors in pediatric patients with brain tumors. The relative CBF showed less variation among studies than the absolute CBF.

ABBREVIATIONS: $a C B F=$ absolute CBF; $A S L=$ arterial spin-labeling; $\mathrm{HGT}=$ high-grade tumor; $\mathrm{LGT}=$ low-grade tumor; $r$ CBF $=$ relative CBF; $Q U A D A S-2=$ Quality Assessment of Diagnostic Accuracy Studies; WHO $=$ World Health Organization

B rain tumors are the second most common tumor affecting children up to 19 years of age. ${ }^{1}$ Preoperative radiologic assessment strives to describe the grade (ie, high- versus low-grade), location, and type of the lesion to guide therapeutic decisions. The

Received January 22, 2018; accepted after revision May 18.

From the Departments of Clinical Neuroscience (Anna F.D.) and Neuroradiology (P.H.), Karolinska Institute, Stockholm, Sweden; Faculty of Medicine and Surgery (F.D.L.), School of Medicine and Health Sciences, University "G. d'Annunzio," Chieti, Italy; Faculty of Medicine (D.v.W.), Clinical Sciences, Lund University, Sweden; and Department of Surgical Sciences (Alberto F.D.), Uppsala University, Uppsala, Sweden.

Anna F.D. received time from the Department of Neuroradiology at Karolinska University Hospital for conducting the study. Karolinska University Hospital has a research agreement with Philips Healthcare on stroke assessment unrelated to this work.

Please address correspondence to Anna Falk Delgado, MD, PhD, Clinical Neuroscience, Karolinska Institute, Stockholm, Sweden, Neuroradiology Department, Karolinska University Hospital, 17176 Solna, Sweden; e-mail: anna.falk-delgado@sll.se spatial location of the lesions differs from that in adults, with pediatric tumors commonly located infratentorially, including the brain stem, which renders surgical resection more difficult. ${ }^{2}$ Location in eloquent areas might delay an operation when the risk of postoperative deficit is weighed against potential longer overall survival, or it may even hamper an operation. Thus, presurgical grading into low- or high-grade tumor, respectively, is of clinical importance for therapeutic and surgical decisions.

In adults, the traditional differentiation between low-grade tumors (LGTs) and high-grade tumors (HGTs), based on the absence or presence of contrast enhancement alone, has proved too simplistic. ${ }^{3,4}$ Previous reports have described the utility of gado-

Indicates article with supplemental on-line tables.

Indicates article with supplemental on-line photos.

http://dx.doi.org/10.3174/ajnr.A5727 
linium-based perfusion MR imaging for differentiation of lowand high-grade tumors in adults. ${ }^{5,6}$ However, children are more susceptible to repeat gadolinium-based contrast agent injection with reportedly increased signal intensity in the dentate nucleus. ${ }^{7}$ A further concern is the nonlinear correlation between contrast enhancement and tumor grade in children, in which grade I tumors (pilocytic astrocytomas) can show vivid enhancement despite the low tumor grade. ${ }^{8,9}$

As an alternative to contrast-enhanced MR perfusion, arterial spin-labeling (ASL) is based on magnetic labeling of water molecules as an endogenous contrast agent. ASL, which provides absolute estimates of CBF, has been proved a valuable tool for adult patients with brain tumors for discriminating LGT and HGT. ${ }^{10-16}$ However, adults and children have divergent tumor types, and the diagnostic value of ASL in pediatric brain tumors has not been fully investigated, to our knowledge.

The value of ASL for cerebral blood flow measurement in pediatric patients with brain tumors has only recently received attention, and reports have shown mainly promising results. ${ }^{17}$ Yet, there is no consensus on the clinical role of ASL, partly due to technical differences, including parameter settings, postprocessing schemes, and analysis methods, in hitherto published studies. A meta-analysis would contribute to the body of evidence on the value of ASL in pediatric brain tumors by evaluating data from different centers using a variety of techniques and elucidating the influence of different aspects of its diagnostic accuracy for discrimination of LGT and HGT. The primary aim of this study was to aggregate the body of evidence on ASL in pediatric patients with brain tumors and to assess the diagnostic accuracy of ASLderived CBF measures to discriminate LGTs and HGTs. In addition, we investigated to what extent variability in the technique and difficulties rendering stable measurements that have previously hampered its wide clinical introduction ${ }^{18}$ influence the validity of CBF measurements using ASL.

\section{MATERIALS AND METHODS}

This meta-analysis was performed according to the Cochrane Handbook for Diagnostic Test Accuracy Reviews ${ }^{19}$ and is reported according to the Preferred Reporting Items for Systematic Reviews and Meta-Analyses 2009 guidelines. ${ }^{20}$ The study design also adhered to current recommendations for diagnostic test accuracy meta-analyses, ${ }^{21}$ and the study protocol was prospectively registered at PROSPERO (CRD42017075055; https://www.crd. york.ac.uk/PROSPERO/).

\section{Eligibility Criteria}

Eligible studies reported ASL data for a pediatric cohort of patients (younger than 18 years of age) with brain tumors. Inclusion criteria were the following: 1) Preoperative MR imaging was performed, including ASL, and 2) postoperative tumor diagnosis was established by histopathology. Further inclusion criteria were that CBF measurements from ASL had been stratified for tumor grade. All ASL techniques were considered eligible for inclusion. Studies presenting data on both absolute and relative CBF were considered for inclusion. Studies reporting recurrent tumors, longitudinal follow-up, adults, or single case reports were excluded. The previously classified diffuse intrinsic pontine gliomas were ex- cluded for 2 reasons: 1) Current World Health Organization (WHO) 2016 guidelines that differ from those in 2007 and recognize diffuse midline gliomas as grade IV, and 2) errors in tissue sampling or lack of neuropathologic information in included studies due to the eloquent location.

\section{Search Strategy and Selection Criteria}

A literature search strategy was developed by a researcher with 9 years' experience in meta-analysis along with a librarian with 5 years' experience in conducting systematic searches (On-line Fig 1). The electronic search was performed at the Karolinska Institutet University Library, including the following databases: MEDLINE (Ovid), Embase.com, the Web of Science Core Collection, and the Cochrane Library (Wiley). The MeSH-terms identified for searching MEDLINE (Ovid) were adapted in accordance with the corresponding vocabulary in EMBASE (On-line Tables 6-9). Each search concept was complemented with relevant freetext terms like "brain tumor," "choroid plexus neoplasm," "astrocytoma," "arterial spin labeling" and "ASL." The free-text terms were, if appropriate, truncated and/or combined with proximity operators. Conference abstracts were excluded. No language restriction was applied. Data bases were searched from inception until January 8, 2018. Retrieved hits were assessed for inclusion independently by 2 researchers with 9 years' and 1 year's experience in meta-analyses, respectively, and were checked for congruency. Incongruences in the data extraction were solved through discussion until a consensus was reached or by consulting a third researcher with 4 years' experience in meta-analysis.

\section{Data Items and Extraction}

Data from each eligible study were extracted independently by 2 researchers onto preformed sheets developed for this study. They extracted the following parameters: mean and maximum absolute (aCBF) or relative CBF ( $\mathrm{rCBF}$ ) - that is, the ratio of signal intensity in the lesion over signal intensity in the contralateral normalappearing cortical gray matter, for example, in the cerebellum or the temporal lobe, in LGT and HGT. In addition, the number of patients, patient age, WHO classification, general anesthesia (yes/ no), study first author, year of publication, study region origin, MR imaging scanner model and manufacturer, number of channels in the head coil used, field strength Tesla, ASL technique (pseudocontinuous or pulsed), TR, TE, number of partitions, flip angle, postlabeling delay (milliseconds), postprocessing, acquisition time, ROI technique, and reference region were extracted. Any incongruences in the data extraction were solved as mentioned above.

\section{Bias Assessment}

Risk of bias in the individual studies was assessed by the revised Quality Assessment of Diagnostic Accuracy Studies (QUADAS-2) tool. ${ }^{22}$ One author with 9 years of experience adapted the QUADAS-2 template to fit the assessment of studies included and added relevant questions for each item. Two researchers independently performed a risk of bias assessment based on the published articles and supplementary material if available. Each item in the QUADAS-2 tool was scored as either "low," "high," or "indeterminate" risk of bias for each of the individual studies or applica- 


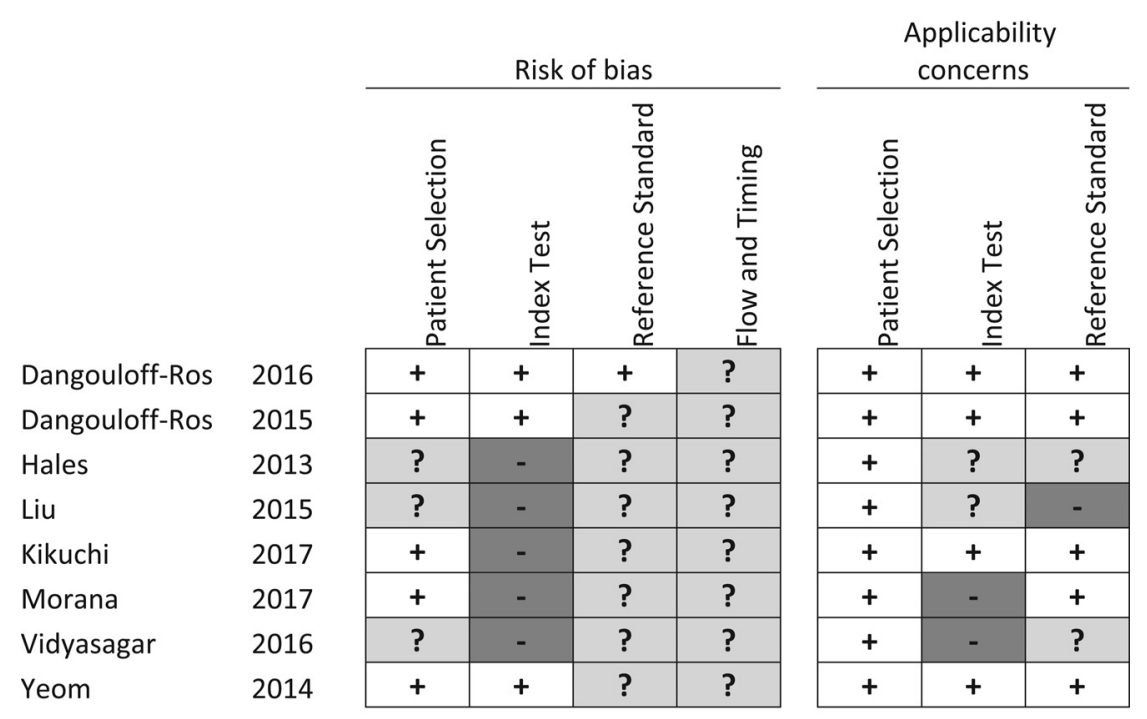

+ indicates low risk

- indicates high risk

? indicates unclear risk

FIG 1. Risk of bias. Patient selection: it is low if consecutive or reported in years of inclusion together with clear inclusion criteria. Unclear if no mention of consecutive series of patients. High if a nonconsecutive series was reported. Index test: low if ASL was interpreted blinded. Unclear if no information on blinding but a predefined cutoff was specified for a positive test. High if an exploratory cutoff was used and no information on blinding was given. Reference standard: low if reported on a blinded evaluation and WHO adherence. Unclear if no information on blinding was given. High if reported on an unblinded evaluation. Flow and timing: low if $<30$ days between ASL and histopathology. Unclear if not reported. High if reported after $>6$ months. Applicability concerns. Patient selection: low if mixed tumor types. Unclear if tumor types were not reported or only 1 tumor type was reported. High if other comparisons than between high- and low-grade were given. Index test: low if presented as relative CBF from 3D pseudocontinuous ASL. Unclear if CBF was not normalized but pseudocontinuous ASL was used. High if perfusion metrics other than CBF were presented or if pulsed ASL was used. Reference standard: low if tumors were classified according to WHO 2007 or later. Unclear if WHO was used but the year was unspecified. High if no report on the histopathologic diagnosis classification system.

bility concerns of studies regarding the main outcome of this meta-analysis.

\section{Statistical Analysis}

The sensitivity and specificity of aCBF/rCBF to discriminate LGT and HGT in the studies were used to calculate the true-positive, truenegative, false-positive, and false-negative counts. In studies reporting individual patient data, $\mathrm{aCBF}$ and $\mathrm{rCBF}$ from each individual were used to calculate the receiver operating characteristic and contingency $(2 \times 2)$ table data, including the optimal cutoff.

The mean difference in $\mathrm{aCBF} / \mathrm{rCBF}$ and its corresponding 95\% confidence interval between LGT and HGT was presented using the inverse variance statistical method with the randomeffects analysis model for the effects measure in RevMan (http:// community.cochrane.org/help/tools-and-software/revman-5). ${ }^{23}$

The univariate measures of sensitivity and specificity for aCBF and $\mathrm{rCBF}$ to discriminate LGT from HGT were calculated for eligible studies. ${ }^{24}$ To take into account the inverse relationship between sensitivity and specificity in diagnostic-accuracy studies, we applied a bivariate approach using the restricted maximum likelihood estimation method. The bivariate summary receiver operating characteristic curve described the overall diagnostic performance of ASL to differentiate LGT and HGT, with a corresponding $95 \%$ confidence interval for sensitivity and specificity. ${ }^{24}$
Heterogeneity was explored by bivariate meta-regression. Statistical analyses were prespecified and analyzed in RevMan $^{23}$ and in $R$ statistical and computing software (http://www.r-project. org), ${ }^{25}$ implementing the $\operatorname{mada}^{24}$ and pROC $_{\text {packages. }}{ }^{26}$

\section{RESULTS}

\section{Search Results}

The systematic search yielded 105 hits before deduplication. Sixty-one hits remained after removing duplicates and were screened for inclusion in the meta-analysis. Thirty-nine articles were excluded after title and abstract assessment, with 22 articles remaining for fulltext evaluation. After full-text evaluation, 14 studies were excluded for the following reasons: 12 having no pediatric cohort, 1 review article, and 1 having no quantitative data available. Eight studies including 286 patients were included in the meta-analysis. ${ }^{17,27-33}$ The study selection is presented in the On-line Figure 1.

\section{Study Characteristics}

Study characteristics of 8 included studies are presented in On-line Table 1, with ASL sequences and study specifications in On-line Tables 2-5. Most (6 of 8 studies) included studies used 3Dpseudocontinuous ASL. ${ }^{17,27-29,32,33}$ Two studies used pulsed ASL. ${ }^{30,31}$ Four of 8 studies used 1.5T, with the remaining using 3T. Risk of bias within studies as assessed by the QUADAS-2 tool, which showed a general low or indeterminate risk of bias (Fig 1). High risk of bias was attributed to undefined blinding procedures when analyzing the ASL data and applying the exploratory cutoff determination in 5 of 8 studies. ${ }^{28-31,33}$ High risk of applicability concern was found in 3 studies $^{29-31}$ : One study did not report a clear description of the reference standard, ${ }^{29}$ and 2 studies applied pulsed $\mathrm{ASL}^{30,31}$ as well as a unique (for the meta-analysis cohort) postprocessing method of vascular crushing. ${ }^{31}$ Applicability concerns were taken into account in the subgroup analyses by stepwise exclusion.

\section{Mean Difference in CBF between Low- and High-Grade Tumors}

The mean difference in aCBF showed a significantly higher CBF in HGT compared with LGT; the mean difference for aCBF was $29.62 \mathrm{~mL} / \mathrm{min} / 100 \mathrm{~g}(95 \% \mathrm{CI}, 10.43-48.82 \mathrm{~mL} / \mathrm{min} / 100 \mathrm{~g})$. The test for overall effect $(Z)$ was $3.03(P=.002)$, and for rCBF, 1.34 $\mathrm{mL} / \mathrm{min} / 100 \mathrm{~g}(95 \% \mathrm{CI}, 0.95-1.74 \mathrm{~mL} / \mathrm{min} / 100 \mathrm{~g})(P<.001)$, depicted in Tables 1 and 2. Reported or calculated optimal cutoffs for the discrimination of low- and high-grade tumors are pre- 
Table 1: Absolute CBF in low- and high-grade tumors with associated results from meta-analysis of mean data ${ }^{a}$

\begin{tabular}{|c|c|c|c|c|c|c|c|c|}
\hline \multirow[b]{2}{*}{ Study } & \multicolumn{3}{|c|}{ High-Grade Tumors } & \multicolumn{3}{|c|}{ Low-Grade Tumors } & \multirow[b]{2}{*}{ Weight } & \multirow{2}{*}{$\begin{array}{l}\text { Mean Difference, IV, } \\
\text { Random-Effects, } \\
95 \% \mathrm{Cl}(\mathrm{aCBF})\end{array}$} \\
\hline & $\begin{array}{l}\text { Mean } \\
\mathrm{aCBF}\end{array}$ & SD & $\begin{array}{l}\text { Total } \\
\text { (No.) }\end{array}$ & $\begin{array}{l}\text { Mean } \\
\text { aCBF }\end{array}$ & SD & $\begin{array}{l}\text { Total } \\
\text { (No.) }\end{array}$ & & \\
\hline Dangouloff-Ros et al, $2015^{27}$ & 239 & 94.75 & 2 & 81.14 & 33.92 & 7 & $1.90 \%$ & $157.86(24.16-291.56)$ \\
\hline Dangouloff-Ros et al, $2016^{17}$ & 80.12 & 47.31 & 65 & 31.6 & 10.39 & 52 & $24.20 \%$ & $48.52(36.68-60.36)$ \\
\hline Hales et al, $2013^{28}$ & 111.5 & 2.12 & 2 & 80.33 & 29.66 & 6 & $18.80 \%$ & $31.17(7.26-55.08)$ \\
\hline Kikuchi et al, $2017^{33}$ & 46.33 & 22.89 & 7 & 19.89 & 21.33 & 11 & $20.10 \%$ & $26.44(5.31-47.57)$ \\
\hline Liu et al, $2015^{29}$ & 53.52 & 17.4 & 6 & 47.32 & 14.74 & 6 & $21.50 \%$ & $6.20(-12.05-24.45)$ \\
\hline Morana et al, $2017^{30}$ & 0 & 0 & 0 & 0 & 0 & 0 & & Not estimable \\
\hline Vidyasagar et al, $2016^{31}$ & 68.75 & 31.77 & 4 & 51.3 & 42.87 & 19 & $13.50 \%$ & $17.45(-19.17-54.07)$ \\
\hline Yeom et al, $2014^{32}$ & 0 & 0 & 0 & 0 & 0 & 0 & & Not estimable \\
\hline Total $(95 \% \mathrm{CI})$ & & & 86 & & & 101 & $100 \%$ & $29.62(10.43-48.82)$ \\
\hline
\end{tabular}

Note:-IV indicates inverse variance.

${ }^{a}$ Heterogeneity: $\tau^{2}=360.34, \chi^{2}=19.31, d f=5(P=.002) ; I^{2}=46 \%$; Test for overall effect: $Z=3.03(P=.002)$

Table 2: Relative CBF in low- and high-grade tumors with associated results from meta-analysis of mean data ${ }^{a}$

\begin{tabular}{|c|c|c|c|c|c|c|c|c|}
\hline \multirow[b]{2}{*}{ Study } & \multicolumn{3}{|c|}{ High-Grade Tumors } & \multicolumn{3}{|c|}{ Low-Grade Tumors } & \multirow[b]{2}{*}{ Weight } & \multirow{2}{*}{$\begin{array}{l}\text { Mean Difference, } \\
\text { IV, Random-Effects } \\
95 \% \mathrm{Cl} \text { (rCBF) }\end{array}$} \\
\hline & $\begin{array}{c}\text { Mean } \\
\text { rCBF }\end{array}$ & SD & $\begin{array}{l}\text { Total } \\
\text { (No.) }\end{array}$ & $\begin{array}{c}\text { Mean } \\
\text { rCBF }\end{array}$ & SD & $\begin{array}{l}\text { Total } \\
\text { (No.) }\end{array}$ & & \\
\hline Dangouloff-Ros et al, $2015^{27}$ & 3.4 & 0.99 & 2 & 0.9 & 0.26 & 7 & $7.10 \%$ & $2.50(1.11-3.89)$ \\
\hline Dangouloff-Ros et al, $2016^{17}$ & 1.74 & 1.45 & 65 & 0.68 & 0.24 & 52 & $37.50 \%$ & $1.06(0.70-1.42)$ \\
\hline Hales et al, $2013^{28}$ & 0 & 0 & 0 & 0 & 0 & 0 & & Not estimable \\
\hline Kikuchi et al, $2017^{33}$ & 1.76 & 0.95 & 7 & 0.69 & 0.81 & 11 & $15.40 \%$ & $1.07(0.22-1.92)$ \\
\hline Liu et al, $2015^{29}$ & 0 & 0 & 0 & 0 & 0 & 0 & & Not estimable \\
\hline Morana et al, $2017^{30}$ & 2.08 & 0.98 & 14 & 0.81 & 0.56 & 12 & $23.90 \%$ & $1.27(0.67-1.87)$ \\
\hline Yeom et al, $2014^{32}$ & 2.98 & 1.9 & 21 & 1.12 & 0.36 & 32 & $16.20 \%$ & $1.86(1.04-2.68)$ \\
\hline Total $(95 \% \mathrm{Cl})$ & & & 109 & & & 114 & $100 \%$ & $1.34(0.95-1.74)$ \\
\hline
\end{tabular}

Note:-IV indicates inverse variance.

a Heterogeneity: $\tau^{2}=0.13, \chi^{2}=9.28, d f=5(P=.10) ; I^{2}=46 \%$; Test for overall effect: $Z=5.94(P<.00001)$

sented in Table 1. Heterogeneity regarding the results was lower for relative $\mathrm{CBF}$ compared with absolute $\mathrm{CBF}$.

\section{Summary Receiver Operating Characteristics}

Absolute CBF. Distributions of the sensitivity and specificity for aCBF ranged between 0.69 and 0.92 for sensitivity and from 0.63 to 0.93 for specificity. ${ }^{17,27-29,33}$

The bivariate summary receiver operating characteristic curve described an area under the curve of 0.90. Excluding pilocytic astrocytomas and the subgroup of posterior fossa tumors in the study by Dangouloff-Ros et al $2016^{17}$ only slightly affected the diagnostic performance (area under curve $=0.88$ ). Excluding 1 study with a high risk of applicability concern of the reference standard in QUADAS-2 did not lower the overall diagnostic performance to discriminate low- and high-grade tumors (area under curve $=0.92) .{ }^{29}$ Bivariate meta-regression found no moderating effect on the outcome (sensitivity or specificity) by TE, TR, acquisition time, or ROI method (maximum or mean CBF) $(P>.05)$.

Relative CBF. rCBF univariate measures of sensitivity and specificity are presented in On-line Fig 2 and ranged between 0.75 to 0.94 for sensitivity and from 0.79 to 0.92 for the specificity. The bivariate summary receiver characteristics curve depicted in Fig 2 described the area under the curve to discriminate LGT and HGT by $\mathrm{rCBF}$ as 0.92 . In sensitivity analysis, excluding pilocytic astrocytomas and the subgroup of posterior fossa tumors in the study by Dangouloff-Ros et al $2016^{17}$ did not increase the diagnostic performance (area under curve $=0.91$ ). Excluding 1 study that used pulsed $\mathrm{ASL}^{30}$ did not increase the diagnostic performance (area under curve $=0.88$ ). In agreement with the subgroup anal- ysis of pulsed-ASL or 3D-pseudocontinuous had no moderating effect on the outcome (sensitivity or specificity) in bivariate metaregression $(P>.05)$. Furthermore, bivariate meta-regression found no moderating effect on the outcome by TE, TR, or acquisition time $(P>.05)$.

\section{DISCUSSION}

This meta-analysis found an aggregated high diagnostic accuracy for cerebral blood flow measurements derived from ASL MR imaging to discriminate LGT and HGT in pediatric patients. Preoperative indications of tumor grade can be important when considering different treatment strategies, clinical decisions related to the timing of treatment, surgical strategies, and prognosis and in longitudinal follow-up of patients.

Factors that might potentially affect the results were analyzed to gain an understanding of the diagnostic potential of ASL, depending on technical properties and patient-specific factors. Both the sensitivity and specificity of ASL-derived CBF measurements were taken into account in evaluating the overall summary receiver operating characteristic curve and when exploring the role for potential moderators of the effect size.

This report is in accordance with a previous meta-analysis evaluating ASL in an adult population that reported the standardized mean differences in CBF between LGT and HGT, ${ }^{10}$ even though pediatric brain tumors have different biologic properties though similar histology. ${ }^{34}$

Our results show that the diagnostic accuracy to discriminate brain tumor grades in children is similar to previous reports evaluating perfusion MR using gadolinium injection in a pediatric cohort. ${ }^{35}$ 
SROC curve (bivariate model) for rCBF in low-grade and high-grade tumors

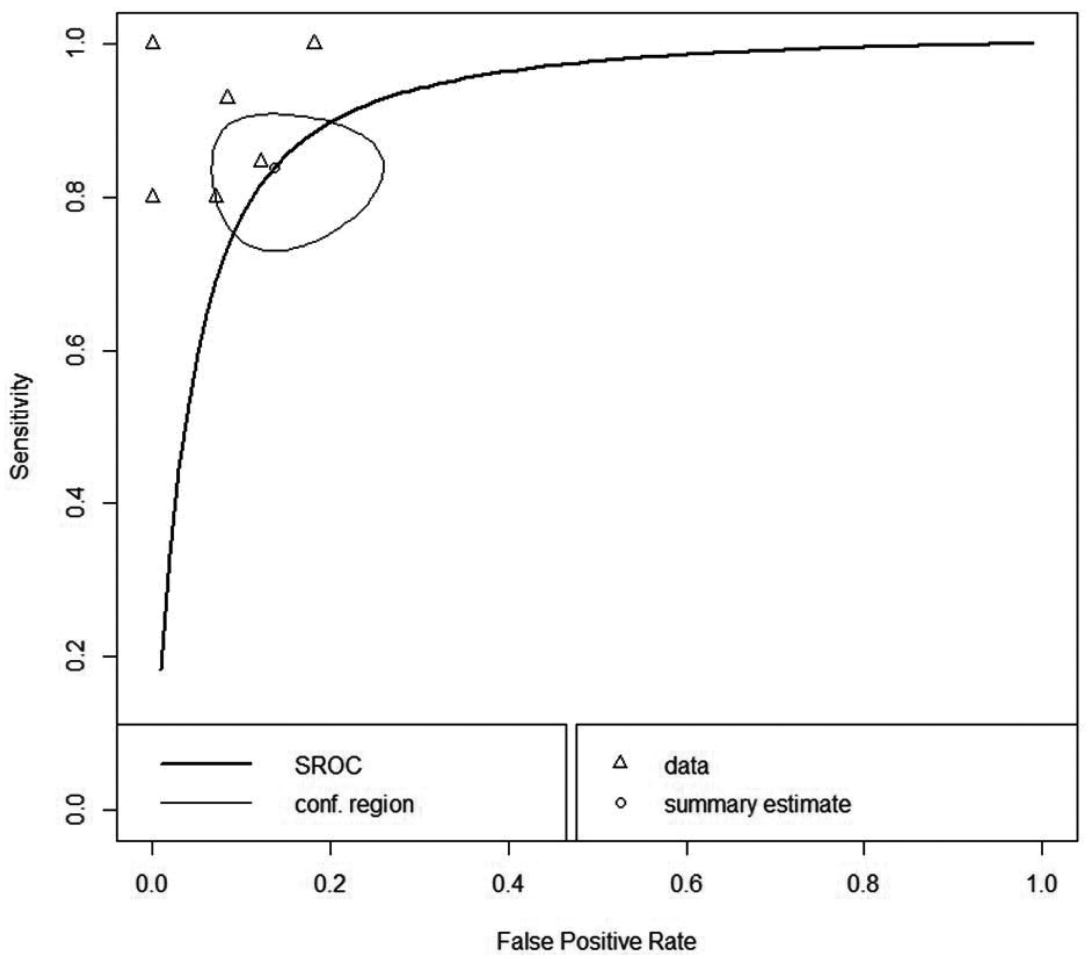

FIG 2. Summary of the receiver operating characteristic curve (bivariate model) for the discrimination of low- and high-grade tumors by relative CBF. The curved line describes the variation in sensitivity and false-positive rate (1-specificity) across the data depicted by open triangles and the open circle, indicating the summary estimate surrounded by the confidence region illustrated by the thinner black line. The area under the curve was 0.92 . SROC indicates summary receiver operating characteristic; conf, confidence.

The use of ASL seems justified in children due to its noninvasive nature, with lack of contrast agent injection and lack of radiation exposure. Pediatric patients subject to MR imaging and not having an intravenous line might thus be investigated with brain MR imaging rendering both morphologic and physiologic data on perfusion without gadolinium-based contrast agent injection.

The ASL technique has been available for $>2$ decades without being introduced in full in the clinic. ${ }^{36-41}$ This study, including original studies published between 2013 and 2017, provides evidence that ASL is approaching an introduction in clinical practice for the evaluation of pediatric brain tumors. There have been concerns raised that ASL would be an immature and unreliable perfusion technique regarding low signal-to-noise ratio, ${ }^{42,43}$ the influence of physiologic fluctuations on the blood flow, ${ }^{43}$ and the effects of anesthesia. ${ }^{44}$

Although absolute CBF is desirable, ASL-derived CBF shows high variation among subjects due to global physiologic factors such as hematocrit, sex, age, and cardiovascular disease. ${ }^{45-47}$ In addition, ASL-derived CBF measurements can be variable when the pulse sequences and postprocessing algorithms are not standardized. ${ }^{48}$ Due to the variability of the tumors in individual studies in this meta-analysis, estimated and reported cutoffs for the discrimination of low- and high-grade tumors varied among studies even when data acquisition was similar (3D pseudocontinuous arterial spin/labeling). However, the cutoff for relative $\mathrm{CBF}$ varied less than that for absolute CBF. For studies reporting relative $\mathrm{CBF}$ in intra-axial brain tumors, cutoffs were more similar.

The impact of age on measurements has not been fully accounted for in the included studies nor has a standardized measurement been used across studies. Representative measurement of tumor blood flow might be hampered by partial volume effects in ASL.

Our study shows that slight parameter changes between study protocols did not have a moderating effect on the diagnostic accuracy. Most included studies applied the 3D-pseudocontinuous ASL technique. Pseudocontinuous ASL has a high repeatability among scanners, and examinations are in accordance with findings in previous reports. ${ }^{18,49}$ Although not immediately evident in our study, the 3D technique has been shown to be superior to $2 \mathrm{D} .^{50}$

Future research in this field should be directed toward the evaluation of other indications when a noninvasive evaluation of blood flow could give important clinical information and possibly also continue to extend the method to calculate cerebral blood volume, mean transit time, ${ }^{51}$ and permeability. ${ }^{52-54}$ An additional advantage of ASL could be the possibility of quantitative measured perfusion. Furthermore, the impact of CBF measurement on overall survival and longitudinal follow-up should be evaluated.

We strove to diminish the influence of publication bias by also searching for gray literature in scientific data bases. Second, the number of included studies is quite small, in part reflecting the difficulty in evaluating pediatric patients with rare diseases and new techniques. However, the included studies comprised 286 patients from several different centers in the world. Included articles mainly used the 2007 WHO brain tumor classification. One measure that was used to adapt to the 2016 classification of brain tumors was to exclude midline gliomas located in the pons. This decision was supported by the lack of a histologic sample from some of these patients due to the eloquent location of these tumors.

\section{CONCLUSIONS}

Available data on the applicability of ASL in children with brain tumors indicate a high diagnostic accuracy to discriminate lowand high-grade tumors. Relative CBF showed less variation between studies compared with absolute CBF.

\section{ACKNOWLEDGMENTS}

We thank Klas Moberg, Librarian at the Karolinska Institute Library, for planning and conducting the search. 
Disclosures: Anna Falk Delgado_RELATED: Other: Department of Neuroradiology Karolinska University Hospital; UNRELATED: Grants/Grants Pending: EU-financed unrelated research project*. *Money paid to the institution.

\section{REFERENCES}

1. Patel S, Bhatnagar A, Wear C, et al. Are pediatric brain tumors on the rise in the USA? Significant incidence and survival findings from the SEER database analysis. Childs Nerv Syst 2014;30:147-54 CrossRef Medline

2. Spennato P, Nicosia G, Quaglietta L, et al. Posterior fossa tumors in infants and neonates. Childs Nerv Syst 2015;31:1751-72 CrossRef Medline

3. Pallud J, Capelle L, Taillandier L, et al. Prognostic significance of imaging contrast enhancement for WHO grade II gliomas. Neuro Oncol 2009;11:176-82 CrossRef Medline

4. $\mathrm{Hu} \mathrm{J}, \mathrm{Wu} \mathrm{W}, \mathrm{Zhu} \mathrm{B}$, et al. Cerebral glioma grading using Bayesian network with features extracted from multiple modalities of magnetic resonance imaging. PLoS One 2016;11:e0153369 CrossRef Medline

5. Santarosa C, Castellano A, Conte GM, et al. Dynamic contrast-enhanced and dynamic susceptibility contrast perfusion MR imaging for glioma grading: preliminary comparison of vessel compartment and permeability parameters using hotspot and histogram analysis. Eur J Radiol 2016;85:1147-56 CrossRef Medline

6. Young R, Babb J, Law M, et al. Comparison of region-of-interest analysis with three different histogram analysis methods in the determination of perfusion metrics in patients with brain gliomas. $J$ Magn Reson Imaging 2007;26:1053-63 CrossRef Medline

7. Flood TF, Stence NV, Maloney JA, et al. Pediatric brain: repeated exposure to linear gadolinium-based contrast material is associated with increased signal intensity at unenhanced T1-weighted MR imaging. Radiology 2017;282:222-28 CrossRef Medline

8. de Fatima Vasco Aragao M, Law M, Batista de Almeida D, et al. Comparison of perfusion, diffusion, and MR spectroscopy between lowgrade enhancing pilocytic astrocytomas and high-grade astrocytomas. AJNR Am J Neuroradiol 2014;35:1495-502 CrossRef Medline

9. Alkonyi B, Nowak J, Gnekow AK, et al. Differential imaging characteristics and dissemination potential of pilomyxoid astrocytomas versus pilocytic astrocytomas. Neuroradiology 2015;57:625-38 CrossRef Medline

10. Kong L, Chen H, Yang Y, et al. A meta-analysis of arterial spin labelling perfusion values for the prediction of glioma grade. Clin Radiol 2017;72:255-61 CrossRef Medline

11. Zeng Q, Jiang B, Shi F, et al. 3D pseudocontinuous arterial spinlabeling imaging in the preoperative evaluation of gliomas. AJNR Am J Neuroradiol 2017;38:1876-83 CrossRef Medline

12. Haller S, Zaharchuk G, Thomas DL, et al. Arterial spin labeling perfusion of the brain: emerging clinical applications. Radiology 2016; 281:337-56 CrossRef Medline

13. Warmuth C, Gunther M, Zimmer C. Quantification of blood flow in brain tumors: comparison of arterial spin labeling and dynamic susceptibility-weighted contrast-enhanced MR imaging. Radiology 2003;228:523-32 CrossRef Medline

14. Chawla S, Wang S, Wolf RL, et al. Arterial spin-labeling and MR spectroscopy in the differentiation of gliomas. AJNR Am J Neuroradiol 2007;28:1683-89 CrossRef Medline

15. Kim HS, Kim SY. A prospective study on the added value of pulsed arterial spin-labeling and apparent diffusion coefficients in the grading of gliomas. AJNR Am J Neuroradiol 2007;28:1693-99 CrossRef Medline

16. Noguchi T, Yoshiura T, Hiwatashi A, et al. Perfusion imaging of brain tumors using arterial spin-labeling: correlation with histopathologic vascular density. AJNR Am J Neuroradiol 2008;29: 688-93 CrossRef Medline

17. Dangouloff-Ros V, Deroulers C, Foissac F, et al. Arterial spin labeling to predict brain tumor grading in children: correlations between histopathologic vascular density and perfusion MR imaging. Radiology 2016;281:553-66 CrossRef Medline
18. Gevers S, van Osch MJ, Bokkers RP, et al. Intra- and multicenter reproducibility of pulsed, continuous and pseudo-continuous arterial spin labeling methods for measuring cerebral perfusion. J Cereb Blood Flow Metab 2011;31:1706-15 CrossRef Medline

19. Leeflang MM, Deeks JJ, Takwoingi Y, et al. Cochrane Diagnostic Test Accuracy Reviews. Syst Rev 2013;2:82 CrossRef Medline

20. Moher D, Liberati A, Tetzlaff J, et al; PRISMA Group. Preferred Reporting Items for Systematic Reviews and Meta-Analyses: the PRISMA statement. PLoS Med 2009;1;6:e1000097 CrossRef Medline

21. McGrath TA, Alabousi M, Skidmore B, et al. Recommendations for reporting of systematic reviews and meta-analyses of diagnostic test accuracy: a systematic review. Syst Rev 2017;6:194 CrossRef Medline

22. Whiting PF, Rutjes AW, Westwood ME, et al; QUADAS-2 Group. QUADAS-2: a revised tool for the quality assessment of diagnostic accuracy studies. Ann Intern Med 2011;155:529-36 CrossRef Medline

23. Review. Version RevMan 5.3. Copenhagen: The Nordic Cochrane Centre, The Cochrane Collaboration, 2014. http://community.cochrane. org/help/tools-and-software/revman-5/revman-5-download. Accessed 2 May 2017

24. Doebler P, Holling H. Meta-Analysis of diagnostic accuracy studies with mada. https://cran.r-project.org/web/packages/mada/vignettes/ mada.pdf. Accessed 16 Sept 2016

25. R Development Core Team (2010). R: A Language and Environment for Statistical Computing. Vienna, Austria: R Foundation for Statistical Computing. http://www.R-project.org. Accessed: 19 April 2017

26. Robin X, Turck N, Hainard A, et al. pROC: an open-source package for $\mathbf{R}$ and $\mathrm{S}+$ to analyze and compare ROC curves. BMC Bioinformatics 2011;12:77 CrossRef Medline

27. Dangouloff-Ros V, Grevent D, Pagès $M$, et al. Choroid plexus neoplasms: toward a distinction between carcinoma and papilloma using arterial spin-labeling. AJNR Am J Neuroradiol 2015;36: 1786-90 CrossRef Medline

28. Hales PW, Phipps KP, Kaur R, et al. A two-stage model for in vivo assessment of brain tumor perfusion and abnormal vascular structure using arterial spin labeling. PLoS One 2013;8:e75717 CrossRef Medline

29. Liu HL, Chang TT, Yan FX, et al. Assessment of vessel permeability by combining dynamic contrast-enhanced and arterial spin labeling MRI. NMR Biomed 2015;28:642-49 CrossRef Medline

30. Morana G, Piccardo A, Tortora D, et al. Grading and outcome prediction of pediatric diffuse astrocytic tumors with diffusion and arterial spin labeling perfusion MRI in comparison with 18FDOPA PET. Eur J Nucl Med Mol Imaging 2017;44:2084-93 CrossRef Medline

31. Vidyasagar R, Abernethy L, Pizer B, et al. Quantitative measurement of blood flow in paediatric brain tumours: a comparative study of dynamic susceptibility contrast and multi time-point arterial spin labelled MRI. Br J Radiol 2016;89:20150624 CrossRef Medline

32. Yeom KW, Mitchell LA, Lober RM, et al. Arterial spin-labeled perfusion of pediatric brain tumors. AJNR Am J Neuroradiol 2014;35: 395-401 CrossRef Medline

33. Kikuchi K, Hiwatashi A, Togao O, et al. Correlation between arterial spin-labeling perfusion and histopathological vascular density of pediatric intracranial tumors. J Neurooncol 2017;135:561-69 CrossRef Medline

34. Louis DN, Perry A, Reifenberger G, et al. The 2016 World Health Organization Classification of Tumors of the Central Nervous System: a summary. Acta Neuropathol 2016;131:803-20 CrossRef Medline

35. Dallery F, Bouzerar R, Michel D, et al. Perfusion magnetic resonance imaging in pediatric brain tumors. Neuroradiology 2017;59:1143-53 CrossRef Medline

36. Alsop DC, Detre JA. Reduced transit-time sensitivity in noninvasive magnetic resonance imaging of human cerebral blood flow. J Cereb Blood Flow Metab 1996;16:1236-49 CrossRef Medline

37. Alsop DC, Detre JA. Multisection cerebral blood flow MR imaging 
with continuous arterial spin labeling. Radiology 1998;208:410-16 CrossRef Medline

38. Detre JA, Alsop DC. Perfusion magnetic resonance imaging with continuous arterial spin labeling: methods and clinical applications in the central nervous system. Eur J Radiol 1999;30:115-24 CrossRef Medline

39. Detre JA, Zhang W, Roberts DA, et al. Tissue specific perfusion imaging using arterial spin labeling. NMR Biomed 1994;7:75-82 CrossRef Medline

40. Silva AC, Zhang W, Williams DS, et al. Multi-slice MRI of rat brain perfusion during amphetamine stimulation using arterial spin labeling. Magn Reason Med 1995;33:209-14 CrossRef Medline

41. Williams DS, Detre JA, Leigh JS, et al. Magnetic resonance imaging of perfusion using spin inversion of arterial water. Proc Natl Acad Sci U S A 1992;89:212-16 CrossRef Medline

42. Spann SM, Kazimierski KS, Aigner CS, et al. Spatio-temporal TGV denoising for ASL perfusion imaging. Neuroimage 2017;157:81-96 CrossRef Medline

43. Chen Y, Wang DJ, Detre JA. Test-retest reliability of arterial spin labeling with common labeling strategies. J Magn Reson Imaging 2011;33:940-49 CrossRef Medline

44. Venkatraghavan L, Poublanc J, Bharadwaj S, et al. Noninvasive measurement of cerebral blood flow under anesthesia using arterial spin labeling MRI: a pilot study. J Neurosurg Anesthesiol 2016;28: 331-36 CrossRef Medline

45. Ibaraki $M$, Shinohara $Y$, Nakamura $K$, et al. Interindividual variations of cerebral blood flow, oxygen delivery, and metabolism in relation to hemoglobin concentration measured by positron emission tomography in humans. J Cereb Blood Flow Metab 2010;30: 1296-305 CrossRef Medline

46. Henriksen OM, Kruuse C, Olesen J, et al. Sources of variability of resting cerebral blood flow in healthy subjects: a study using ${ }^{133} \mathrm{Xe}$ SPECT measurements. J Cereb Blood Flow Metab 2013;33:787-92 CrossRef Medline
47. Xu F, Li W, Liu P, et al. Accounting for the role of hematocrit in between-subject variations of MRI-derived baseline cerebral hemodynamic parameters and functional BOLD responses. Hum Brain Mapp 2018;39:344-53 CrossRef Medline

48. Alsop DC, Detre JA, Golay X, et al. Recommended implementation of arterial spin-labeled perfusion MRI for clinical applications: a consensus of the ISMRM perfusion study group and the European consortium for ASL in dementia. Magn Reson Med 2015;73:102-16 CrossRef Medline

49. $\mathrm{Wu} \mathrm{B}$, Lou $\mathrm{X}, \mathrm{Wu} \mathrm{X}$, et al. Intra- and interscanner reliability and reproducibility of 3D whole-brain pseudo-continuous arterial spin-labeling MR perfusion at 3T. J Magn Reson Imaging 2014;39: 402-09 CrossRef Medline

50. Kilroy E, Apostolova L, Liu C, et al. Reliability of two-dimensional and three-dimensional pseudo-continuous arterial spin labeling perfusion MRI in elderly populations: comparison with 150 -water positron emission tomography. J Magn Reson Imaging 2014;39: 931-39 CrossRef Medline

51. van Westen D, Petersen ET, Wirestam R, et al. Correlation between arterial blood volume obtained by arterial spin labelling and cerebral blood volume in intracranial tumours. MAGMA 2011;24: 211-23 CrossRef Medline

52. Bibic A, Knutsson L, Schmidt A, et al. Measurement of vascular water transport in human subjects using time-resolved pulsed arterial spin labelling. NMR Biomed 2015;28:1059-68 CrossRef Medline

53. Hales PW, Clark CA. Combined arterial spin labeling and diffusionweighted imaging for noninvasive estimation of capillary volume fraction and permeability-surface product in the human brain. J Cereb Blood Flow Metab 2013;33:67-75 CrossRef Medline

54. Wang J, Fernández-Seara MA, Wang $\mathrm{S}$, et al. When perfusion meets diffusion: in vivo measurement of water permeability in human brain. J Cereb Blood Flow Metab 2007;27:839-49 CrossRef Medline 